\title{
TRABALHO DIDÁTICO E ESCOLARIZAÇÃO PRIMÁRIA: FONTES PARA A HISTÓRIA DA EDUCAÇÃO NO FINAL DO IMPÉRIO
}

\author{
Analete Regina Schelbauer \\ arschelbauer@uem.br \\ Universidade Estadual de Maringá - UEM
}

\begin{abstract}
RESUMO:
O objetivo deste artigo é apresentar algumas considerações iniciais acerca das fontes documentais relacionadas ao processo de escolarização primária e a organização do trabalho didático, tomando a Província de São Paulo e o final dos oitocentos como lócus de análise. Dentre essas fontes destacamos as Atas do Conselho Superior de Instrução Pública da Província de São Paulo e os Relatórios de Escolas Particulares e de Professores Públicos Primários, que fazem parte do Acervo de fontes manuscritas do Arquivo do Estado de São Paulo (AESP). Este trabalho contempla parte das reflexões apresentadas durante a MesaRedonda "História e trabalho didático", realizada durante o VIII Seminário Nacional do Grupo de Estudos e Pesquisas "História, Sociedade e Educação no Brasil" - HISTEDBR, no ano de 2009.
\end{abstract}

Palavras-chave: História da Educação; Fontes Documentais; Escolarização Primária; Trabalho Didático.

\section{LABOR TEXBOOK AND TEACHING PRIMARY: SOURCES FOR THE HISTORY OF EDUCATION AT THE END OF EMPIRE}

\begin{abstract}
:
The objective of this article is to present some initial considerations about the documentary sources related to the process of primary education and organization of the labor textbook, taking the Province of Sao Paulo-Brazil and the end of the eight hundred as the locus of analysis. Among these sources highlight the proceedings of the Board of Education in the Province of São Paulo and the Report of Private Schools and Public Primary Teachers who are part of the manuscript sources of the Archives of the State of Sao Paulo (AESP). This work comprises part of the comments made during the Round Table "History and the labor textbook," realized during the Eighth National Seminar of the Study and Research "History, Society and Education in Brazil" - HISTEDBR in the year of 2009.

Keywords: History of Education; Documentary Source; Primary Schooling, Labor Textbook.

\section{1 - Introdução}

O objetivo deste artigo é apresentar algumas considerações iniciais acerca das fontes documentais relacionadas ao processo de escolarização primária e a organização do trabalho didático, tomando a Província de São Paulo e o final dos oitocentos como lócus de análise.
\end{abstract}


Este trabalho contempla algumas reflexões apresentadas durante a Mesa-Redonda "História e trabalho didático", realizada como parte das atividades do VIII Seminário Nacional do Grupo de Estudos e Pesquisas "História, Sociedade e Educação no Brasil" HISTEDBR, em $2009^{1}$, tendo como interlocutores os professores Gilberto Luiz Alves e José Carlos de Souza Araújo².

“A Organização do Trabalho Didático na História da Educação" já figurou enquanto tema da VII Jornada do HISTEDBR, realizada em 2007, com relevo específico durante suas conferências e mesas-redondas. O tema foi proposto diante da necessidade de ampliar a divulgação e o debate, no interior do Grupo, em torno das pesquisas historiográficas sobre a educação e, de modo específico, "aquelas que tomam como singular o interior da escola". O resultado dos trabalhos culminou com o livro organizado por Brito, Centeno, Lombardi e Saviani, intitulado "A organização do trabalho didático na história da educação", com publicação prevista para 2010.

A temática também foi objeto do livro de Alves (2005), "O trabalho didático na escola moderna. Formas históricas", o qual representa um marco inaugural, dentre as análises da historiografia filiadas à ciência da história. Para esta linha investigativa, o trabalho didático é analisado como categoria que incorpora: a relação histórica educadoreducando; a mediação exercida pelos procedimentos do professor, pelos conteúdos didáticos e pelas tecnologias educacionais e a materialidade espacial e arquitetônica onde tal relação se dá.

Alves (2005) salientou que o tema - trabalho - quase sempre é retomado no campo da educação pelos pesquisadores filiados ao HISTEDBR. No entanto, os estudos e pesquisas em torno do trabalho didático, voltado ao entendimento das formas históricas pelas quais ele se efetiva na relação pedagógica, ainda se configura como um campo inicial. Neste sentido, a iniciativa do debate em torno do tema, no interior das Jornadas e Seminários, tem contribuído para a articulação entre os pesquisadores dos diversos Grupos de Trabalho, assim como para a produção acadêmica na área.

Diante disto e do pressuposto que cada época produz uma forma histórica de organização do trabalho didático, nossa interlocução com o tema proposto relaciona-se com a trajetória da pesquisa acerca da escola pública que tem sido nosso foco de análise nas últimas décadas.

Para efeito da escrita do artigo, optamos por abordar a questão proposta à mesa tendo presente os dois aspectos anunciados no título deste artigo, a saber, o processo de escolarização primária no Brasil e os elementos de organização do trabalho didático no final dos oitocentos. Neste cenário de difusão da escolarização primária, diversos aspectos entram em evidência: o método baseado nos procedimentos e recursos didáticos do ensino intuitivo; a formação do professor na escola normal; os conteúdos escolares voltados à formação intelectual, moral e física; os manuais didáticos que passam a traduzir os princípios do método e servir como guia pelo professor; os exames escolares; os materiais didáticos, dentre outros relacionados à estrutura física, material e temporal dos espaços escolares e a própria legislação do ensino.

Com este cenário, são infinitas as possibilidades de estudos que emergem a partir do olhar do pesquisador sobre as fontes. Neste artigo, apresento algumas das fontes 
documentais que permitem analisar questões relacionadas à organização da escola primária e do trabalho didático no final do XIX.

É importante salientar o movimento de difusão da escolarização primária que se inicia em fins do século XIX, evidenciado nos debates, prescrito nas reformas da instrução pública e concretizado nas práticas escolares. Esse movimento, que se instaura por volta dos anos de 1870, ganha ênfase no decorrer da década de 1880 e, sobretudo, durante a década de 1890, quando se consubstanciam as reformas republicanas da instrução pública, coloca em evidencia figuras de intelectuais de destaque no cenário educacional e concretiza importantes iniciativas vinculadas ao movimento de renovação pedagógica.

Dentre as fontes documentais que nos permitem acompanhar traços desse movimento na Província de São Paulo, destacamos as Atas do Conselho Superior de Instrução Pública da Província de São Paulo e os Relatórios de Escolas Particulares e dos Professores Públicos Primários.

Esses documentos fazem parte do acervo de fontes manuscritas, da Série Instrução Pública, do Arquivo do Estado de São Paulo (AESP). Neste conjunto de fontes, encontramos uma vasta documentação proveniente das escolas públicas e particulares da província de São Paulo tais como: relatórios de professores públicos de primeiras letras; atas de exames escolares das escolas primárias e da Escola Normal da Capital; papéis sobre concursos às cadeiras da instrução pública; relatórios de inspetores distritais; relatórios dos diretores das escolas particulares; prospectos e programas de ensino; reminiscências apresentadas por ex-alunos das escolas, cartas, ofícios diversos, documentos históricos, dispositivos legais relativos à organização do ensino elementar, enfim, uma extensa documentação que nos permitiu, sobretudo, adentrar no interior da organização do trabalho didático nas últimas décadas do império na província de São Paulo. Além destas, é preciso destacar a imprensa periódica republicana, os impressos da hemeroteca do Arquivo. Jornais que tiveram papel fundamental como veículo de difusão e circulação, no Brasil, das inovações educacionais em curso na Europa e Estados Unidos.

A série de Ofícios Diversos do Arquivo do Estado de São Paulo já foi objeto de capítulo publicado por Hilsdorf, em 1999, no qual ressaltou a importância da documentação, que na época permanecia praticamente inédita, como fonte para a escrita da história da educação e da escolarização em São Paulo nos séculos XVIII, XIX e XX.

A importância do trabalho com os manuscritos do AESP é qualificada por Hilsdorf $(1999$, p. 15) não apenas pela quantidade dos dados que o acervo oferece, "mas pelo fato destes serem trazidos à luz em função de uma certa compreensão do campo pesquisado".

Nossa trajetória de investigação junto à documentação do Arquivo teve início no ano de 1999, em meio às definições das fontes e do problema de pesquisa do doutorado que culminaria, em 2003, com a tese intitulada "A constituição do método de ensino intuitivo na província de São Paulo (1870-1889)" (SCHELBAUER, 2003). A opção por precisar o recorte temporal no final do século XIX, na transição entre o Império e a República, se deu em meio ao debate a respeito da importância deste período para a história da educação brasileira.

Vidal e Souza (1999, p. 7) ressaltam que "figuras da precariedade, dos professores improvisados, permearam durante muito tempo o imaginário histórico a respeito da 
educação no Império e na transição Império/República". Para as autoras, foi somente a partir de um amplo debate crítico a respeito da produção desse imaginário, desencadeado por historiadores de diversos locais e instituições, a partir de distintos referenciais teóricos e diferentes indagações "que a educação brasileira do século XIX passou a ser iluminada como território, suscitando questões que tocam no nervo da especificidade da formação escolar no Brasil".

Foi no decorrer do século XIX, de acordo com Saviani (2004, p. 28), que se delineou o processo gradual de organização da escolarização primária. Esse movimento que implicou na exigência de um espaço apropriado para o desenvolvimento da instrução, cominou na organização dos grupos escolares no período republicano.

Retirar da "sombra" o século XIX, para usar a metáfora empregada no título da obra organizada por Vidal e Souza (1999) "A memória e a sombra. A escola brasileira entre o Império e a República", tem feito parte dos esforços de pesquisas de inúmeros historiadores da educação brasileira na última década. Com isso, têm sido imensuráveis as contribuições sobre o período. Dos objetos às fontes, os oitocentos têm sido revisitados trazendo "luz" sobre a organização da escola primária e do trabalho pedagógico que nela se desenvolveu antes mesmo de sua disseminação no período republicano. Neste sentido, vamos ao encontro de algumas das fontes que podem nos ajudar a iluminar esse período de constituição da escolarização primária e do trabalho didático.

\section{2 - As Atas do Conselho Superior de Instrução Pública}

As Atas do Conselho Superior de Instrução Pública da Província de São Paulo, que integram o acervo de fontes manuscritas do Arquivo do Estado de São Paulo (AESP), ainda permanecem no rol dos documentos a serem pesquisados. As atividades do Conselho foram referenciadas nos trabalhos de Hilsdorf (1986), Reis Filho (1995), Schelbauer (2003), Tavares (2004), dentre outros, e configuram-se como uma importante fonte documental para a história da educação brasileira, sobretudo para compreensão da organização da escola primária e dos elementos do trabalho didático nos últimos anos do Império e na transição Império/República.

O Conselho Superior de Instrução Pública foi criado pela Reforma de 1887, sancionada em seis de abril, pela Lei n. 81, pelo Barão do Parnaíba e seu respectivo Regulamento da Instrução Pública Provincial data de 22 de agosto ${ }^{3}$. Além do Conselho Superior, são criados os Conselhos Municipais, a figura do Diretor e a Secretaria da Instrução Pública. São estabelecidos os concursos, como requisito para a nomeação dos professores públicos. Determina-se que as escolas públicas primárias só poderiam ser regidas por normalistas ou por pessoas habilitadas por concurso feito perante o Conselho. Divide-se a instrução primária em três graus "apropriados à idade e ao desenvolvimento intelectual dos alunos". A "lição de coisas com observação espontânea" é definida como matéria do programa dessas escolas, acrescentado a observação de que: "as lições serão mais empíricas do que teóricas e o professor se esforçará por transmitir aos seus discípulos noções claras e exatas da matéria, provocando o desenvolvimento gradual das faculdades" (SCHELBAUER, 2003).

O Conselho teve sua existência marcada por dois momentos: o primeiro de 1887 a 1890; e o segundo de 1893 a 1897. Tendo como cenário os anos finais do Império, o 
Conselho Superior de Instrução Pública da Província de São Paulo iniciou suas atividades em 5 de outubro de 1887, data da $1^{\text {a }}$. Sessão Ordinária, realizada na cidade de São Paulo. O Conselho foi presidido por Vieira de Carvalho e composto por José Vicente, Arthur Guimarães, Frederico Abranches, Rabelo e Silva, Leite de Moraes, Brasílio Machado, Reverendo Valois de Castro e Cônego Manoel Vicente ${ }^{4}$.

Uma das primeiras determinações do Conselho foi a organização do Programa para o concurso das cadeiras vagas da instrução primária na província. Elaborou também, além de seu Regimento Interno, o Regimento Interno das Escolas Primárias da Província e as demais reformas referentes ao ensino público.

Em sua breve existência no período monárquico, o Conselho legou à república as prescrições relacionadas à organização do trabalho didático, traduzidas no Regimento Interno das Escolas Primárias (1887), que propunha medidas relativas à direção e fiscalização do ensino, ao plano geral de ensino, as matérias das escolas primárias, os programas, os métodos e demais instruções ao professorado quanto à organização do ensino primário.

Após várias sessões negativas, as atividades do Conselho foram encerradas no ano de 1890: "aos 22 dias do mês de março de 1890, nesta cidade de São Paulo, às 14 horas, achando-se presente somente o cidadão Arthur C. Guimarães, não houve sessão por falta absoluta de número legal, para constar lavrou-se a presente ata negativa" (Ordem 1162) ${ }^{5}$.

Mas, no ano de 1893 o Conselho Superior de Instrução Pública foi reaberto, tendo suas atividades sancionadas pela Lei republicana no. 88, de $1992^{6}$. De acordo com Reis Filho (1995, p. 116), o Conselho foi instalado solenemente no dia 3 de maio de 1893, tendo iniciado seus trabalhos com os seguintes conselheiros:

a) Doutor Artur César Guimarães, Diretor Geral da Instrução Pública. b) José Estácio Correia de Sá e Benevides, Diretor Interino da Escola Normal da Capital. c) Miss Márcia Browne, Diretora da Escola-Modelo. d) Doutor Isaías Vilaça, representante das Câmaras Municipais. e) Ernesto Rodrigues Goulart Penteado, representante do Professorado Público.

Nas reflexões de Reis Filho (1995, p. 117), o Conselho Superior de Instrução Pública de 1893 foi um antecessor longínquo do atual Conselho Estadual de Educação na medida em que executava funções de fiscalização, de direção, execução, julgamento, assessoria e consultoria. Neste período de funcionamento, o Conselho cuidou:

...do regulamento das escolas preliminares; do regimento interno delas; de casas para essas escolas; de livros e materiais escolares; da adoção de livros de escrituração escolar livros didáticos, mapas, etc. Organizou um memorandum pra permitir o exercício das funções de inspetores distritais, enquanto estavam em elaboração as normas regulamentares daqueles órgãos.

Em agosto de 1897, o Conselho foi suprimido pela Lei $520^{7}$. Em quase quatro anos de sua primeira fase (1887-1890), ainda no final do Império, e pouco mais de quatro anos já no período republicano (1893-1897), esse órgão de direção e inspeção da instrução 
pública paulista, legou a história da escola primária e da organização do trabalho didático importante contribuição na discussão, elaboração e regulamentação das questões relativas às condições materiais das escolas e a organização didático-pedagógica do ensino primário.

\section{3 - Os relatórios de escolas particulares e de professores públicos primários}

No âmbito das concretizações empreendidas quanto à organização do trabalho didático, as escolas particulares, de iniciativa individual ou associada, voltadas a educação do povo ou das elites, destacam-se por sua posição de vanguarda quanto às inovações pedagógicas em curso. Seus documentos constituem-se em importante fonte de pesquisa para compreensão da questão em foco neste artigo. Dentre essas escolas, podemos citar: a Escola Americana (São Paulo, 1870), o Colégio Internacional (Campinas, 1872), o Colégio Culto à Ciência (Campinas, 1874), o Instituto do Novo Mundo (Itu, 1875), o Colégio Pestana (Capital 1876), o Colégio Morton (Capital, 1880), o Colégio Piracicabano (Piracicaba, 1881), o Liceu de Artes e Ofícios (Capital, 1882), a Escola Primária Neutralidade (fundada oficialmente na capital, em 1884, mas cujas origens remontam a 1878, com o Colégio Kopke, e 1879, com a Escola Modelo), dentre outras iniciativas de menor expressão.

Essas escolas, reconhecidas como "geradoras de inovações", criadas no período de transição entre o Império e a República em diversas províncias, foram objeto de vários estudos no âmbito da historiografia educacional e constituem-se em importante fonte para o estudo acerca da organização do trabalho didático.

Outra fonte de fundamental importância para a história da escolarização primária e do trabalho didático são os Relatórios individuais e semestrais dos professores públicos das cadeiras de primeiras letras da província de São Paulo. De acordo com o previsto nos Regulamento de 18 de abril de $1869^{8}$ e de 22 de agosto de 1887 , esses professores eram obrigados a encaminhar, semestralmente, relatório versando sobre o estado da sua escola e o adiantamento de seus discípulos ao Inspetor da Instrução Pública. Na prática, os relatórios continham informações sobre matrícula, freqüência, aproveitamento dos alunos, casa escolar, mobília, utensílios escolares, matérias ensinadas e métodos utilizados, dentre outros aspectos.

Estes documentos também compõem o acervo de fontes manuscritas da Série Instrução Pública do AESP. Encontram-se organizados em latas e catalogados com a seguinte especificação: Instrução Pública. Ensino Particular. Ofícios sem localidade; e Instrução Pública. Relatórios das localidades, separadas por número de ordem e lata, com indicação de período de abrangência da documentação. No caso dos relatórios das escolas públicas, estão separados por localidades de A-Z, cada lata contém em torno de 200 papéis. As localidades abrangem desde a Capital até as cidades do interior da Província.

Nesses relatórios é possível vislumbrar os elementos da organização do trabalho didático, aqui tomados de acordo com a acepção de Alves (2005), compreendendo a relação histórica entre o educador e o educando, a mediação exercida pelos procedimentos do professor, pelos conteúdos, métodos de ensino e recursos didáticos e pela materialidade espacial e arquitetônica onde tal relação se dá, é expressa pelos professores de primeiras letras da província de São Paulo. Nesses documentos, há descrições significativas de novas práticas escolares, de livros didáticos que chegavam ao conhecimento desses professores, assim como de matérias de ensino e métodos considerados inovadores para a 
época. Sem desconsiderar, contudo, as dificuldades relatadas quanto às condições precárias a que eles estavam sujeitos, sobretudo os professores das cadeiras públicas de primeiras letras.

No âmbito do ensino público, a prática dos relatórios irá acompanhar a implantação das escolas-modelo e dos Grupos Escolares, que passam a co-existir com as escolas isoladas e as escolas reunidas no período republicano.

Para o pesquisador, esses documentos permitem acompanhar as modificações que se processaram no interior das escolas públicas de primeiras letras no final do Império e, posteriormente, nos anos iniciais da República.

\section{4 - Considerações finais}

Conforme salientamos no início dessa exposição, nosso propósito foi tecer algumas considerações em torno das fontes documentais relacionadas à constituição do trabalho didático no processo de difusão da escola primária no Brasil, em fins do século XIX.

O período histórico delimitado - imediatamente anterior a escola pública propriamente dita, na acepção de Saviani (2005) - coloca-nos diante de um acervo significativo de fontes que permitem problematizar e compreender os pontos essenciais do projeto republicano de escolarização - e sua consequente organização do trabalho didático. Essas fontes nos informaram sobre a constituição de um percurso conflituoso ao evidenciar as inovações pedagógicas em curso, as prescrições legais e os relatos das condições concretas, disponibilizadas aos professores, nas escolas de primeiras letras.

O exame das fontes nos permite problematizar a complexidade de seu uso para a história da organização do trabalho didático, sobretudo, em relação aos relatórios de professores. Esses relatos, produzidos por uma exigência legal - Regulamento de Ensino vigente - são fontes significativas, pois trazem o discurso dos professores e, nele, elementos que nos permitem compreender a forma como se propõe a organizar e realizar o trabalho didático no interior da escola.

No caso específico deste artigo, os relatórios analisados situam-se nos anos de 1880, período caracterizado, no âmbito das tematizações, pela crítica ao ensino primário ofertado e mantido pela monarquia e a defesa da renovação do ensino como condição essencial para a modernização da nação.

Essas fontes, enquanto produções humanas e, portanto, históricas, disponibilizados em arquivos, bibliotecas e nas próprias instituições educacionais, são documentos, registros que foram acumulados e guardados, mas que só adquirem o estatuto de fonte diante do historiador, como salientou Saviani (2004, p. 6-7), que "ao formular o seu problema de pesquisa, delimitará aqueles elementos a partir dos quais serão buscadas as respostas às questões levantadas".

Dentre as inúmeras questões que emergem a partir da temática da organização do trabalho didático, uma diversidade de fontes documentais, orais e iconográficas, nos são disponibilizados pelos acervos públicos ou privados, nos arquivos, bibliotecas e instituições educacionais. Isso nos remete, necessariamente, a algumas delimitações e 
recortes prévios, tanto relacionados ao espaço quanto ao tempo histórico e social em que ele se organiza.

No caso de tomarmos os relatórios de professores como fontes para a história da organização do trabalho didático, é importante observar que debruçar-se sobre os elementos do fazer pedagógico, não afasta essa especificidade da relação educativa que se insere no plano macro, das teorias educacionais, das políticas públicas, das inovações em larga escala as quais estão circunscritas a um contexto histórico e social determinados.

Como segunda consideração, gostaríamos de ressaltar que os estudos em torno objeto - trabalho didático - podem lançar novas luzes para a reconstrução histórica das instituições escolares, sobretudo, para a história da escola pública no Brasil, campo que tem se configurado como uma das tendências de Grupo na atualidade.

Além disso, as pesquisas sobre a temática podem contribuir para a compreensão do debate histórico em torno da relação teoria e prática, expressas na dicotomia existente entre as disciplinas de fundamentos da educação e as disciplinas de didática e metodologia, que configuram a formação de professores.

Ainda, no âmbito da formação de professores, a história da organização do trabalho didático permite um campo de entrada na composição dos programas de disciplinas como a didática, as metodologias de ensino específicas e a própria alfabetização, ao trazer a organização do trabalho didático, nessas áreas, mediante a análise histórica. Compreender a organização do trabalho didático, por meio de investigações de caráter histórico, pode concorrer para redimensionar o campo das práticas escolares, da didática, visto tradicionalmente como um campo distinto, inserindo-o nos demais elementos da relação educativa ou pedagógica, sob o olhar histórico.

Por fim, as lições da história nos alertam para a necessidade de correlacionar as dimensões dos discursos, das prescrições legais e das concretizações ou pelo menos de sua intenção, quando pensamos na organização do trabalho didático.

É importante salientar que as fontes documentais aqui apresentadas, traduzidas nas discussões relatadas nas Atas do Conselho Superior de Instrução Pública e nas práticas pedagógicas descritas pelos professores primários, ao trazerem questões relativas à organização da escolarização primária e do trabalho didático, evidenciam ao historiador o importante legado que os anos finais do Império e da transição Império/República deixaram para a história da educação brasileira, sobretudo, para a história da escola pública. 


\section{Referências}

ANAIS do VIII Seminário Nacional do Grupo de Estudos e Pesquisas "História, Sociedade e Educação no Brasil” - HISTEDBR, 2009. História, Educação e Transformação:

Tendências e Perspectivas. Campinas-SP, 2009.

ANAIS da VII Jornada do Grupo de Estudos e Pesquisas "História, Sociedade e Educação no Brasil" - HISTEDBR. A organização do trabalho didático na história da educação. Campo Grande-MS, 2007.

ALVES, Gilberto Luiz. O trabalho didático na escola moderna. Campinas-SP: Autores Associados, 2005.

BRITO, Silvia; CENTENO, Carla; LOMBARDI, José Claudinei; SAVIANI, Dermeval. A organização do trabalho didático na história da educação. Campinas-SP: Autores Associados, 2010 (Prelo).

HILSDORF, Maria Lucia. A série ofícios diversos do arquivo do estado de São Paulo como fonte para a história da educação brasileira. In: VIDAL, Diana; SOUZA, Maria Cecília. (Orgs.). A memória e a sombra: a escola brasileira entre o Império e a República. Belo Horizonte-MG: Autêntica 1999, p. 13-19.

HILSDORF, Maria Lucia. Francisco Rangel Pestana: jornalista, político, educador. 1986. Tese (Doutorado em Educação) - Faculdade de Educação, Universidade de São Paulo, São Paulo, 1986.

REIS FILHO, Casemiro dos. A educação brasileira e a ilusão liberal. São Paulo: Cortez; Campinas-SP: Autores Associados, 1995.

SAVIANI, Dermeval. Breves considerações sobre fontes para a história da educação. In: LOMBARDI, José Claudinei; NASCIMENTO, Maria Isabel Moura (orgs.). Fontes, história e historiografia da educação. Campinas-SP: Autores Associados, 2004.

SAVIANI, Dermeval. História da Escola Pública no Brasil: questões para pesquisa. In: LOMBARDI, José Claudinei; SAVIANI, Dermeval; NASCIMENTO, Maria Isabel Moura (orgs.). A escola pública no Brasil. História e Historiografia. Campinas-SP: Autores Associados, 2005.

SCHELBAUER, Analete Regina. A constituição do método de ensino intuitivo na província de São Paulo (1870-1889). 2003. Tese (Doutorado em Educação) Faculdade de Educação, Universidade de São Paulo, São Paulo, 2003.

TAVARES, Fausto Antonio Ramalho. Na marcha do ensino. Organização Burocrática do Ensino Estadual no São Paulo Republicano. 1892-1910. 2004. Tese (Doutorado em Educação) - Faculdade de Educação, Universidade de São Paulo, São Paulo, 2004.

VIDAL, Diana; SOUZA, Maria Cecília C. C. (orgs.). A memória e a sombra: a escola brasileira entre o império e a república. Belo Horizonte-MG: Autêntica, 1999. 


\section{Fontes:}

ATAS das Sessões do Conselho Superior de Instrução Pública da Província de São Paulo (1887-1893). Ordem 1162.

LEI n.81, de 6 de abril e Regulamento de 22 de agosto de 1887. In: COLEÇÃO de Leis e Posturas Provinciais promulgadas pela Assembléia Legislativa Provincial de São Paulo em 1887. São Paulo: Tipografia do Correio Paulistano, 1887.

LEI no. 88, de 8 de setembro de 1892. Coleção das Leis e Decretos do Estado de São Paulo, tomo II, $3^{\text {a }}$ Edição, Imprensa Oficial.

LEI n.54, de 15 de abril de 1868 e Regulamento da Instrução Pública da Província de São Paulo, de 18 de abril de 1869. In: COLEÇÃO de Leis e Posturas Provinciais promulgadas no ano de 1868 e 1869. São Paulo: Tipografia do Correio Paulistano, 1869.

Notas: ${ }^{1}$ O VIII Seminário do HISTEDBR, realizado no período de 30 de julho a 03 de julho de 2009, teve como
tema central "História, Educação e Transformação: Tendências e Perspectivas".

2 As discussões apresentadas pelos professores estão contempladas nos artigos desta edição intitulados: "Manuais didáticos de história do Brasil no Colégio Pedro II: do Império às primeiras décadas da República", de autoria de Gilberto Luiz Alves; e "O trabalho didático do professor no Brasil dos anos de 1920: a aula em foco", de autoria de José Carlos de Souza Araújo, publicados no presente número da Revista HISTEDBR Online.

${ }^{3}$ Lei n॰.81, de 6 de abril e Regulamento de 22 de agosto de 1887. Vide: COLEÇÃO de Leis... 1887.

${ }^{4}$ Vide Ata da $1^{\text {a }}$. Sessão Ordinária realizada em 5 de outubro de 1887 (Ordem 1162. Atas das Sessões do Conselho Superior de Instrução Pública da Província de São Paulo (1887-1893).

5 Vide Ata da Sessão Negativa realizada em 22 de março de 1890 (Ordem 1162. Atas das Sessões do Conselho Superior de Instrução Pública da Província de São Paulo (1887-1893).

${ }^{6}$ Lei no. 88, de 8 de setembro de 1892. Coleção das Leis e Decretos do Estado de São Paulo, tomo II, $3^{\mathrm{a}}$ Edição, Imprensa Oficial.

${ }^{7}$ Ver Reis Filho (1995).

${ }^{8}$ No início da década de 1870 , a instrução primária na província era regulamentada pela Lei n .54 , de 15 de abril de 1868 e Regulamento da Instrução Pública da Província de São Paulo, de 18 de abril de 1869. As escolas eram denominadas cadeiras públicas de primeiras letras e funcionavam em casas particulares. $\mathrm{O}$ ensino consistia nas seguintes matérias: leitura, escrita, princípios elementares de aritmética, sistema métrico de pesos e medidas, noções essenciais de gramática portuguesa, doutrina da religião do Estado e princípios de moral cristã. Quanto à matrícula, era gratuita e os alunos poderiam ser admitidos durante todo o ano letivo, dentre as restrições, não se admitia a co-educação dos sexos, a presença de escravos e menores de cinco anos. Quanto ao tempo do exercício das escolas era das oito horas da manhã a uma hora da tarde (Coleção de Leis e Posturas Provinciais, 1869).

Artigo recebido em: 02/09/2009

Aprovado para publicação em: 10/09/2009

Revista HISTEDBR On-line, Campinas, n.35, p. 220-229, set.2009 - ISSN: 1676-2584 